\title{
Are Nonprescription Sunglasses in Ethiopian Market Protective for Ultraviolet Radiation?
}

This article was published in the following Dove Press journal: Clinical Optometry

\section{Haile Woretaw Alemu Nebiyat Feleke Adimassu}

Department of Optometry, College of Medicine and Health Sciences, University of Gondar, Gondar, Ethiopia
Correspondence: Nebiyat Feleke Adimassu

Department of Optometry, College of Medicine and Health Sciences, University of Gondar, Gondar, Ethiopia

Tel +251918035619

Email neby.uog@gmail.com
Background: Nonprescription sunglasses are available in bulk from authorized and unauthorized vendors. Sunglasses should follow the minimum requirements to sufficiently protect the eyes. In this study, we found that a significant proportion of nonprescription sunglasses available at authorized and unauthorized sources were not protective of ultraviolet radiation.

Purpose: Protection from harmful ultraviolet radiation with sunglasses minimizes or avoids ocular complications. In developing countries like Ethiopia, sunglasses are imported without regulation. Sunglasses are distributed to the market without regulatory tests for potential causes of ocular complications. The purpose of this study was to determine commercially available nonprescription sunglasses' ultraviolet radiation protection level.

Methods: A total of 74 pairs of nonprescription sunglasses were collected from different parts of the country and tested for ultraviolet radiation protection using ultraviolet detector (anti-radiation UV sun detector, China) instrument. Brand, lens color and average of three readings of ultraviolet radiation protection were recorded. The International Commission on Non-Ionizing Radiation Protection standard followed. Data were entered and analyzed by using SPSS version 20. Descriptive and analytical statistics were performed.

Results: Of the total 74 different pairs of nonprescription sunglasses, $47.3 \%$ (35) were obtained from authorized sources and $86.5 \%(\mathrm{p}=0.23)$ were brand tagged. Only $73.0 \%$ $(\mathrm{p}=0.81)$ of nonprescription sunglasses were in accordance with the standards and protective to ultraviolet radiation, while the remaining $27.0 \%(\mathrm{p}=0.59)$ were failed to block the harmful ultraviolet radiation. Upon one sample $t$-test, the mean ultraviolet radiation protection level of commercially available sunglasses was 392.77 ( $t$-value $=-7681.54, \mathrm{p}<0.001)$.

Conclusion: Significant proportions of nonprescription sunglasses available from vendors were not protective of ultraviolet radiation and performed below the expected international standards. Reassurance is mandatory before dispensed to users irrespective of source.

Keywords: ultra-violet, protection, nonprescription, sunglasses, Ethiopia

\section{Introduction}

The sun emits ultraviolet radiation (UVR) waves that range from 200-400 nanometers (nm). Atmospheric ozone layer fully absorbs the harmful ultraviolet-C (UVC) range from 200-280 nm, and partially absorbs ultraviolet-B (UVB) range from 290-315 nm. But ultraviolet-A (UVA) range from 315-400 nm, penetrate the ozone layer and abundantly reached the earth's surface. ${ }^{1,2}$ The extent of UVR exposure increases among people who lived near the equator, higher altitudes and highly reflective surfaces. ${ }^{3,4}$ Also, the intensity of UVR reach on earth's surface increased during the winter season and midday from 10:00 am-4:00 pm. In urban 
places, the risk for ultraviolet radiation intensified as a result of reflective surfaces from buildings, glass windows, asphalt roadways and ceramic surfaces. ${ }^{3,5}$

Prolonged exposure has been linked to serious ocular complications including cataract, corneal degenerations, conjunctival degenerations, retinal degenerations and others. ${ }^{6,7}$

A considerable portion of ocular UVR exposure can be shielded by using a broad-brimmed hat, suitably manufactured wrap-around sunglasses and a combination of both. ${ }^{6,8,9}$ Quality sunglasses blocked UVR up to $400 \mathrm{~nm}$ (filter 99-100\% of UVR) irrespective of color and extent of darkness, maximize comfort, protect from environmental pollutants (debris, dust, wind) and additionally used for the purpose of style. ${ }^{10,11}$

The Ozone depilation due to climate change increased exposure to UVR at the earth's surface. At the equator region, maximum UVR protection with nonprescription sunglass is considered to be compulsory. ${ }^{12-14}$ Because of the study location and maximum safety, this study considered $400 \mathrm{~nm}$ UVR protections as the benchmark supported by various international standards. ${ }^{11,15-17}$ In developed countries, a significant number of studies reported that all branded sunglasses sufficiently protect eyes from UVA and UVB penetration. ${ }^{6}$ Non-branded inexpensive sunglasses also acceptably satisfy the safety requirements of UVR protection. ${ }^{18}$ In the United States, sunglasses are regulated as medical devices by the Food and Drug Administration (FDA). Thus, manufacturers, importers and distributors are aware of all laws and regulations to provide standard and safe sunglasses. ${ }^{19}$

In low- and middle-income countries, sunglass regulation laws were either not existed, loose if existed, or not applied to control manufacturers, distributors, or vendors. Thus, sunglasses provided by unauthorized sellers were alarmingly unreliable and could potentially hazardous for the eyes. ${ }^{20,21}$ Manufacturers lack to explicit the characteristics of sunglass products and simply advertise as UVR absorbing. $^{22}$ The cost of sunglass is not always an indication of good quality in protecting UVR. ${ }^{10}$

Awareness of the harmful effect of UVR to the eyes prompts people to use sunglasses outdoor, yet it is insufficient. A considerable portion of people are still not aware of quality sunglass properties and rely on vendors. ${ }^{10,23,24}$ Wearing poor quality, nonlabelled and cheap sunglasses may expose eyes to the harmful UVR through disabling the eye's natural safety mechanism. This phenomenon maximizes the entrance of harmful UVR to the eyes and even causes damage more than being necked eyes. ${ }^{1,20,25}$
Fewer fake branded and unbranded sunglasses have a poor blocking capacity of UVR. Hence, it is recommended to assess the ultraviolet radiation protection quality of sunglasses before dispensed to users. $^{26}$ To the authors' knowledge, no evidence assured the quality of nonprescription sunglasses in Ethiopia. Therefore, this study aims to assess the ultraviolet protection property of commercially available sunglasses obtained from authorized and unauthorized retailers.

\section{Methods and Materials}

Samples were collected from authorized (permitted by local authorities) and unauthorized (street vendors) sources from April to December 2019. A total of 74 different sample sunglasses were collected from five major cities of the country namely, Gondar, Bahir-Dar, Addis-Ababa, Hawassa and Jigjiga. An effort was made to obtain as diverse brand samples as possible from both sources.

Blinding the sources, sample sunglasses were tagged and given for an optometrist to test ultraviolet protection level using an instrument ultraviolet detector (antiradiation UV sun detector, china). The front surface center of cleaned sunglasses is placed towards the ultraviolet radiation source to take measurements. For consistency, all measurements were taken by a single optometrist and the average of three consecutive readings of ultraviolet cut value was recorded. The readings were compared against the strict ICNIRP standards and sunglasses that blocked UVR wavelength up to $400 \mathrm{~nm}$ were considered safe and comply with the standards. ${ }^{15}$

Data were entered and analyzed by using SPSS software (IBM version 20, SPSS Inc., IL, and USA). Chi-square $(\chi 2)$ test was used for categorical data, and one sample $t$-test to compare against the ICNIRP standard. Independent samples $t$-test was used to compare sources. A P-value $\leq 0.05$ was considered as statistical significance. Ethical clearance was obtained from the University of Gondar, College of Medicine and Health Sciences, School of Medicine ethical review committee. The study was conducted in accordance with the Declaration of Helsinki.

\section{Results}

A total of 74 pairs of sunglasses comprising 35 pairs from authorized and 39 pairs from unauthorized vendors were measured. The majority of sunglasses were designed for male. More than half of sunglasses had labeled as UVR protectors on their lenses. Regarding the tint color, black and brown accounts for the same proportion (Table 1). 
Table I Descriptive Characteristics of Sun Glasses from Authorized and Unauthorized Sellers in Ethiopian Market 2020

\begin{tabular}{|l|l|l|l|}
\hline \multicolumn{2}{|l|}{ Variables } & Frequency & Percentage \\
\hline Brand tagged & Yes & 64 & 86.5 \\
\cline { 2 - 4 } & No & 10 & 13.5 \\
\hline \multirow{4}{*}{ Tint color } & Brown & 35 & 47.3 \\
\cline { 2 - 4 } & Black & 35 & 47.3 \\
\cline { 2 - 4 } & $\begin{array}{l}\text { Mirror } \\
\text { coated }\end{array}$ & 4 & 5.4 \\
\hline \multirow{4}{*}{ User category } & Adult men & 63 & 85.1 \\
\cline { 2 - 4 } & Adult women & 4 & 5.4 \\
\cline { 2 - 4 } & Children & 7 & 9.5 \\
\hline \multirow{2}{*}{$\begin{array}{l}\text { Labeling of } \\
\text { protection }\end{array}$} & Yes & 45 & 60.8 \\
\cline { 2 - 4 } & No & 29 & 39.2 \\
\hline Tint uniformity & Uniform & 53 & 71.6 \\
\cline { 2 - 4 } & Gradient & 21 & 28.4 \\
\hline
\end{tabular}

The two groups were compared by the brand tag (branded, unbranded) and selling price.

From the total sample, majority of the sample (86.5\%) had brand tag. According to ICNIRP standards, from the total 74 samples, $73 \%$ of them had the ability to protect UVR protection up to $400 \mathrm{~nm}$, whereas $27 \%$ of them failed to protect UVR up to $400 \mathrm{~nm}$.

Comparing the sunglasses based on their source from the total of 35 sunglasses obtained from authorized sellers, $26(74.25 \%)$ were passed the standard for UVR protection. From the total of 39 sunglasses obtained from unauthorized sellers, 28 (71.79\%) were passed the standard for UVR protection $(\mathrm{p}=0.81)$. The failure rate to protect up to $400 \mathrm{~nm}$ UVR accounted $28.20 \%$ among 39 sunglasses obtained from unauthorized vendors and $25.71 \%$ among 35 sunglasses obtained from authorized vendors (X2 test $\mathrm{p}=0.81)$ (Table 2).

Among the total of 64 brands tagged nonprescription sunglasses, only $72.0 \%$ (46) has UVR protection capacity up to $400 \mathrm{~nm}$. Out of 10 unbranded nonprescription sunglasses, $80.0 \%$ (8) had UVR protection capacity up to $400 \mathrm{~nm}$.

Upon the one-sample $t$-test, the mean ultraviolet radiation protection level of commercially available sunglasses in Ethiopia was $392.77 \mathrm{~nm}$ ( $\mathrm{t}-\mathrm{value}=-7681.54, \mathrm{p}<0.001$ ) as compared to ICNIRP protection standard value $(400 \mathrm{~nm})$.
Table 2 Characteristics of Sunglasses Obtained from Authorized and Unauthorized Sources in Ethiopian Market 2020

\begin{tabular}{|l|l|l|l|}
\hline Variables & $\begin{array}{l}\text { From } \\
\text { Authorized } \\
(\mathbf{n}=35)\end{array}$ & $\begin{array}{l}\text { Unauthorized } \\
(\mathbf{n}=39)\end{array}$ & $\mathbf{P}$ \\
\hline Branded & $32(91.45)$ & $32(82.05 \%)$ & 0.23 \\
\hline Non branded & $3(8.57 \%)$ & $7(17.94 \%)$ & 0.23 \\
\hline UVR protection passed & $26(74.25 \%)$ & $28(71.79 \%)$ & 0.81 \\
\hline UVR protection failed & $9(25.71 \%)$ & $11(28.20 \%)$ & 0.81 \\
\hline UVR transmission rate & $6.25 \% \pm 2.12$ & $6.47 \% \pm 2.29$ & 0.93 \\
\hline
\end{tabular}

The mean transmission rate of UVR was comparable in sunglasses obtained from unauthorized and authorized vendors ((6.47\%\% vs $6.25 \%)$; independent samples $t$-test $\mathrm{P}=0.93)$ ).

The mean price of sunglasses from authorized (6.31 $\$ \mathrm{USD} \pm 1.26$ SUSD) was high as compared to the mean price of the unauthorized vendors (3.81\$USD $\pm 0.94 \$ \mathrm{USD}$ ).

The mean price of the branded items was higher than the mean price of unbranded sunglasses $(5.11 \$ \mathrm{USD} \pm 1.72$ \$USD and 4.17\$USD $\pm 1.04 \$ U S D$, respectively).

\section{Discussion}

Increasing public awareness about the risk of ultraviolet radiation and the importance of using sunglasses encourage public demand. ${ }^{27}$ Among the sunglass safety properties, protection against UVR radiation was considered the most important and indispensable variable. This study determined nonprescription sunglass UVR protection levels available in the Ethiopian market.

Concerning the strict ICNIRP protection standard of UVR (impervious rays shorter than $400 \mathrm{~nm}$ ), only $73.0 \%$ of the tested nonprescription sunglasses were fulfilled the standard. But the remaining $27.0 \%$ of nonprescription sunglasses available in the Ethiopian market failed to protect the harmful ultraviolet radiation up to $400 \mathrm{~nm}$. This result was lower as compared to $92.6 \%$ protection of nonprescription sunglasses determined by Bazzazi N. ${ }^{20}$ Poor regulation of nonprescription sunglasses during importation, distribution and dispensing to users might contribute for bulk availability of substandard nonprescription sunglasses in the study area. Relaying on brands of nonprescription sunglasses and dispensing before test for UVR protection may likely contribute to poor compliance. 
The UVR protection level of nonprescription sunglasses obtained from authorized (74.2\%) and unauthorized (71.8\%) sources were comparable. There was no association between the UVR protection level of nonprescription sunglasses and sources. This implies obtaining nonprescription sunglasses from authorized sources alone cannot assure safety from UVR protection. This result was against with Adul-Kabir et al study that concludes all nonprescription sunglasses from optical shops met the standard while $53.0 \%$ obtained from roadside vendors failed to meet the standard. ${ }^{28}$ This implicated that in the study area authorized vendors have failed a professional duty to ensure the provision of standard nonprescription sunglasses to the customers.

About 26\% of nonprescription sunglasses obtained from authorized sources were failed to protect UVR up to $400 \mathrm{~nm}$. This was found to be higher as compared to the Iran report $(7.4 \%){ }^{20}$ This outcome suggested the poor regulatory system of commercially available sunglasses even in authorized vendors.

Among all sampled sunglasses, $86.5 \%$ were brand names. This study revealed that the brand tag was not found to be the guarantee for optimal UVR protection. Only $72.0 \%$ (46) of brand tagged and $80 \%$ (8) of unbranded nonprescription sunglasses fulfilled the ICNIRP standard of UVR protection. Being brand tagged and obtained from either authorized or unauthorized sources were not statistically associated with protection quality and safety of nonprescription sunglasses available from vendors. This finding was in line with a study conducted by Leow et $\mathrm{al}^{10}$ but contrary to the result of the Iran study which concludes, the authorized sources provide better quality sunglasses as compared to unauthorized sources. ${ }^{20}$ This contradiction was suggestive of misleading labels and fake branded nonprescription sunglasses circulated in the market which made it difficult to distinguish good quality from the poor-quality. Regulating and testing the quality of nonprescription sunglasses before dispensed to users is necessary to pledge quality safety instead of relying on brand name and high cost.

One sample $t$-test showed that the mean UVR protection level of commercially available nonprescription sunglasses was lower as compared to the ICNIRP strict standard protection level $(400 \mathrm{~nm}) .{ }^{15}$ This finding discovered high amount of sunglasses failed with standard to protect UVR protection. This displayed the presence of poor-quality nonprescription sunglasses available in the market and dispensed to users.
Literally, a high price was used as the benchmark to guarantee the quality of nonprescription sunglasses. The mean price of the branded sunglasses $(163 \pm 40.56)$ was higher than unbranded sunglasses (199.77 \pm 67.28$)$. But the higher cost was not associated with the quality of sunglasses. This result was in line with Leow et al and Dongre et al. ${ }^{10,26}$ According to this study buying sunglass with brand name is not a guarantee for users to distinguish the good from poor UVR protector. This problem also extended to both the authorized and unauthorized sources. Therefore, only regulating and testing the quality of nonprescription sunglasses before dispensed to users can only use to assure the quality instead of relying on brand name and high cost.

Optical's high profit margin attracts industries and optical outlets to invest in the sector. Lack of strict quality control over most of the products manufactured from small-scale industrial units compromises the quality of protection. ${ }^{21}$

\section{Strength and Limitations of the Study}

As a strength, it provides evidence to eye care providers about the obligatory reassurance of nonprescription sunglasses before dispensed to users and generates evidence to regulatory authorities to control it from the sources and from vendors. The quality of the paper will increase if UVR protection was measured by spectrophotometer. Anti-radiation UV sun detector may not be accurate as a spectrophotometer. The inadequate sample size might hide to exploit other enabling or disabling factors such as source, tint color, and brand tag.

\section{Conclusion and Recommendation}

Significant proportion of nonprescription sunglasses obtained from authorized and unauthorized vendors failed to comply with UVR protection standard. As a result, reassuring nonprescription sunglasses against UVR is recommended before dispensed to users. Moreover, strict regulation should be implemented to improve the provision of quality nonprescription sunglasses available in authorized and unauthorized distributors.

\section{Data Sharing Statement}

The datasets used and/or analyzed during the current study can be available from the corresponding author on reasonable request. 


\section{Consent for Publication}

Not applicable.

\section{Acknowledgments}

The authors are grateful to the University of Gondar and Light for the World (LFW) for funding to purchase sample nonprescription sunglasses. We are also thankful to the department of optometry for providing dispensing laboratory facilities.

\section{Author Contributions}

All authors made a significant contribution to the work reported, whether that is in the conception, study design, execution, acquisition of data, analysis and interpretation, or in all these areas; took part in drafting, revising or critically reviewing the article; gave final approval of the version to be published; have agreed on the journal to which the article has been submitted; and agree to be accountable for all aspects of the work.

\section{Funding}

The University of Gondar and alight For the World (LFW) financial support to purchase of samples.

\section{Disclosure}

The authors declare that they have no competing interests.

\section{References}

1. Wang SQ, Balagula Y, Osterwalder U. Photoprotection: a review of the current and future technologies. Dermatol Ther. 2010;23:31-47. doi:10.1111/j.1529-8019.2009.01289.x

2. McKenzie RL, Aucamp PJ, Bais AF, Björn LO, Ilyas M, Madronich S. Ozone depletion and climate change: impacts on UV radiation. Photochem Photobiol Sci. 2011;10:182-198. doi:10.1039/c0pp90034f

3. Tuchinda C, Srivannaboon S, Lim HW. Photoprotection by window glass, automobile glass, and sunglasses. $\mathrm{J} \mathrm{Am}$ Acad Dermatol. 2006;54:845-854. doi:10.1016/j.jaad.2005.11.1082

4. Knezevic J. Impact of high-altitude ultraviolet radiation on functionability of flight crews. Arch Biomed Eng \& Biotechnol. 2019;2:2. doi:10.33552/ABEB.2019.02.000533

5. Parisi AV, Green A, Kimlin MG. Diffuse solar UV radiation and implications for preventing human eye damage. Photochem Photobiol. 2001;73:135-139. doi:10.1562/0031-8655(2001) 073<0135:DSURAI $>2.0 . \mathrm{CO} ; 2$

6. Rosenthal FS, Bakalian AE, Lou CQ, Taylor HR. The effect of sunglasses on ocular exposure to ultraviolet radiation. Am J Public Health. 1988;78:72-74. doi:10.2105/AJPH.78.1.72

7. Delic NC, Lyons JG, Di Girolamo N, Halliday GM. Damaging effects of ultraviolet radiation on the cornea. Photochem Photobiol. 2017;93:920-929. doi:10.1111/php.12686

8. Neale RE, Purdie JL, Hirst LW, Green AC. Sun exposure as a risk factor for nuclear cataract. Epidemiology. 2003;14(6):707-712. doi:10.1097/01.ede.0000086881.84657.98

9. Sakamoto Y, Kojima M, Sasaki K. Effectiveness of eyeglasses for protection against ultraviolet rays. Jpn J Ophthalmol. 1999;43 (6):566-567. doi:10.1016/S0021-5155(99)00125-2
10. Leow YH, Tham SN. UV-protective sunglasses for UVA irradiation protection. Int J Dermatol. 1995;34:808-810. doi:10.1111/j.13654362.1995.tb04405.x

11. Gies P, van Deventer E, Green AC, Sinclair C, Tinker R. Review of the global solar UV index 2015 workshop report. Health Phys. 2018;114:84. doi:10.1097/HP.0000000000000742

12. Masili M, Schiabel H, Ventura L. Contribution to the radiation protection for sunglasses standards. Radiat Prot Dosimetr. 2015;164:435-443. doi:10.1093/rpd/ncu274

13. Grigalavicius M, Moan J, Dahlback A, Juzeniene A. Daily, seasonal, and latitudinal variations in solar ultraviolet $\mathrm{A}$ and $\mathrm{B}$ radiation in relation to vitamin $\mathrm{D}$ production and risk for skin cancer. Int J Dermatol. 2016;55(1):23-28. doi:10.1111/ijd.13065

14. Jablonski NG, Chaplin G. Human skin pigmentation as an adaptation to UV radiation. Proc Natl Acad Sci. 2010;107(2):8962-8968. doi:10.1073/pnas.0914628107

15. International Commission on Non-Ionizing Radiation Protection (ICNIRP). Protecting Workers from Ultraviolet Radiation: ICNIRP 14/2007. Germany: DCM Meckenheim; 2007.

16. Olsen CM, Wilson LF, Green AC, et al. Cancers in Australia attributable to exposure to solar ultraviolet radiation and prevented by regular sunscreen use. Aust NZ J Public Health. 2015;39:471-476. doi: $10.1111 / 1753-6405.12470$

17. Standards Australia/Standards New Zealand. Sunglasses and Fashion Spectacle, AS/NZS 1067:2003. Sydney: Standards Australia International; 2003.

18. Cader A, Jankowski J. Evaluation of protective properties of sunglasses commonly available in the marketplace. Med $\mathrm{Pr}$. 1996;47:365-371.

19. American National Standards Institute (ANSI). Non-Prescription Sunglass and Fashion Eyewear Requirements, ANSI Z80.3-2009. New York: American National Standards Institute; 2009.

20. Bazzazi N, Heydarian S, Vahabi R, Akbarzadeh S, Fouladi DF. Quality of sunglasses available in the Iranian market; a study with emphasis on sellers' license. Indian J Ophthalmol. 2015;63:152. doi:10.4103/0301-4738.154395

21. Velpandian T, Ravi A, Kumari S, Biswas N, Tewari H, Ghose S Short report protection from ultraviolet radiation by spectacle lenses available in India: a comparative study. Natl Med J India. 2005;18:242-244.

22. Mello MM, Lincoln VA, Ventura L. Self-service kiosk for testing sunglasses. Biomed Eng Online. 2014;13:1-11. doi:10.1186/1475-925X-13-45

23. Glavas IP, Patel S, Donsoff I, Stenson S. Sunglasses-and photochromic lens-wearing patterns in spectacle and/or contact lens-wearing individuals. Eye Contact Lens. 2004;30(2):81-84. doi:10.1097/01. ICL.0000113033.88918.E6

24. Maddock JE, O'Riordan DL, Lee T, Mayer JA, McKenzie TL. Use of sunglasses in public outdoor recreation settings in Honolulu, Hawaii. Optom Vis Sci. 2009;86:165. doi:10.1097/OPX.0b013e318194eae7

25. Deleu H, Roelandts R. Protecting the eye from ultraviolet A radiation during photochemotherapy. Photodermatol Photoimmunol Photomed. 1990;7(6):233-236.

26. Khopkar U, Dongre A, Pai G. Ultraviolet protective properties of branded and unbranded sunglasses available in the Indian market in UV phototherapy chambers. Indian J Dermatol Venereol Leprol. 2007;73(1):26. doi:10.4103/0378-6323.30647

27. British Standards Institution (BSI). Personal Eye-Equipment Sunglasses and Sun Glare Filters for General Use and Filters for Direct Observation of the Sun, BS EN 1836:2005. British Standards Institution; 2005.

28. Adul-Kabir M. Ultraviolet-A protection in nonprescription sunglasses. EC Ophthalmology. 2016;3:289-295. 


\section{Publish your work in this journal}

Clinical Optometry is an international, peer-reviewed, open access journal publishing original research, basic science, clinical and epidemiological studies, reviews and evaluations on clinical optometry. All aspects of patient care are addressed within the journal as well as the practice of optometry including economic and business analyses. Basic and clinical research papers are published that cover

Submit your manuscript here: https://www.dovepress.com/clinical-optometry-journal all aspects of optics, refraction and its application to the theory and practice of optometry. The manuscript management system is completely online and includes a very quick and fair peer-review system, which is all easy to use. Visit http://www.dovepress.com/ testimonials.php to read real quotes from published authors. 